\title{
Computation and structural elucidation of compounds formed via epoxide alcoholysis
}

\author{
Elson S. Alvarenga (i) | Milena G. Teixeira | Dayane T. Lopes | Antonio J. Demuner
}

Department of Chemistry, Universidade Federal de Viçosa, Viçosa, Brazil

\section{Correspondence}

Elson S. Alvarenga, Departament of Chemistry, Universidade Federal de Viçosa, Viçosa, MG 36571-900, Brazil. Email: elson@ufv.br

\section{Funding information}

Conselho Nacional de Desenvolvimento Científico e Tecnológico; Coordenação de Aperfeiçoamento de Pessoal de Nível Superior; Fundação de Amparo à Pesquisa do Estado de Minas Gerais

\begin{abstract}
Isobenzofuranones are known for their wide range of biological activities such as fungicide, insecticide, and anticancer. The search for novel bioactive compounds was performed by reaction of epoxide 2 with methanol, ethanol, propan-1-ol, propan-2-ol, and butan-1-ol.

The mechanism for the stereoselective and stereospecific epoxide opening with methanol was reasoned by calculating the transition states for the two putative structures ( $r a c)-3 \mathrm{a}$ and ( $r a c)-3 \mathrm{~b}$. The compound ( $\mathrm{rac}$ )-3a is the kinetic product as inferred from the lower energies of its transition state (TS1). The ${ }^{1} \mathrm{H}$ and ${ }^{13} \mathrm{C}$ nuclear magnetic resonance (NMR) chemical shifts for these two candidate structures were calculated and compared with the experimental data using mean absolute error (MAE) and DP4 analyses. Therefore, the relative stereochemistry of (rac)-3a was established by the mechanism, MAE, and DP4 approaches. The hydroxyl group was acetylated to surpass the problem of signal overlapping of $\mathrm{H} 5$ and $\mathrm{H} 6$ in the ${ }^{1} \mathrm{H}$ NMR. The relative stereochemistry of the corresponding ester determined by NMR interpretation was in agreement with the structure of ( $\mathrm{rac})$-3a.

\section{KEYWORDS}

${ }^{13} \mathrm{C}$ NMR, ${ }^{1} \mathrm{H}$ NMR, DP4, epoxide, isobenzofuranone, MAE, phthalides, $\gamma$-lactones
\end{abstract}

\section{1 | INTRODUCTION}

Isobenzofuranones or phthalides are a class of heterocyclic compounds commonly found in the plant, fungi, and bacteria kingdom. Researches involving isobenzofuranones are receiving a great deal of attention for a long period of time due to the broad bioactivities of these molecules such as fungicide,${ }^{[1]}$ insecticide, ${ }^{[2]}$ and anticancer. ${ }^{[3]}$

Among the methods known for the synthesis of isobenzofuranones, the Diels-Alder cycloaddition, which

Correction added on 18 March 2019, after first online publication: A prefix ' $\mathrm{S}$ ' has been added to the pagination of this article, so the page range has changed from 101-107 to S101-S107. is able of creating two new sigma bonds and up to four stereogenic centers, is frequently employed. ${ }^{[4]}$ The Diels-Alder adduct of this study is obtained by reaction between furan-2 $(5 H)$-one and cyclopentadiene, having in its structure a six-member ring with a double bond. ${ }^{[5]}$ The double bond is functionalized to obtain an epoxide group that, when treated with an alcohol in the presence of acid, is opened to afford hydroxyl and ether groups.

However, the structural elucidation of some compounds sometimes is not promptly achieved by conventional methods as the nuclear magnetic resonance (NMR) due to problems such as overlapping of signals (mainly in ${ }^{1} \mathrm{H}$ spectra), complexity of the molecules, or even insufficient amount of sample. Within this context, computational methods have been used in order to solve 
structural and mechanistic problems by means of programs able to calculate chemical parameters. ${ }^{[6-8]}$

Chemical parameters, like ${ }^{13} \mathrm{C}$ and ${ }^{1} \mathrm{H}$ NMR chemical shifts, are calculated using the density functional theory (DFT) with good accuracy at this level of theory. ${ }^{[9,10]}$ Goodman, with the intention of assigning the structure and stereochemistry of organic molecules, created a probability model named ${ }^{[11]}$ DP4. The theoretical and experimental values of ${ }^{1} \mathrm{H}$ and ${ }^{13} \mathrm{C}$ chemical shifts for the candidate structures are compared and the goodness-of-fit probabilities are given. Apart from DP4, the mean absolute error (MAE, defined as $\left.\Sigma_{\mathrm{n}}\left|\delta_{\text {calc }}-\delta_{\text {exp }}\right| / n\right)$, which is a measure of the difference between the experimental and theoretical ${ }^{1} \mathrm{H}$ and ${ }^{13} \mathrm{C}$ chemical shifts, is a popular method frequently used as a tool to elucidate complex structures. ${ }^{[1-15]}$

In some cases, it has not been possible to determine the relative stereochemistry only from the NMR data; therefore, a methodology for the assignment of the relative stereochemistry using MAE analyses in conjunction with DP4 probability has been employed.

Considering the challenging task of establishing the relative stereochemistry of the hydroxylated isobenzofuranone by the spectroscopic methods, we established the mechanism for the stereoselective and stereospecific epoxide opening with methanol. Apart from ( $r a c)-3 a$, four novel alcohols were prepared by opening of the epoxide 2 with ethanol, propan-1-ol, propan-2-ol, and butanol. The mechanism for the methanol opening of the epoxide 2 was proposed based on the calculated transition states (TSs) for the two candidate structures ( $r a c)-3 a$ and ( $r a c)-$ 3b. Subsequently, the relative stereochemistry of (rac)-3a was confirmed by DFT calculation of the ${ }^{1} \mathrm{H}$ and ${ }^{13} \mathrm{C}$ NMR chemical shifts followed by MAE and DP4 analyses. The signal overlapping of $\mathrm{H} 5$ and $\mathrm{H} 6$ was surpassed by chemical modification of the isobenzofuranone by acetylation of the hydroxyl group.

\section{2 | RESULTS AND DISCUSSION}

The Diels-Alder adduct 1 prepared as described in the literature, was reacted with meta-chloroperbenzoic acid (MCPBA) to afford $^{[2]}$ the epoxide 2 . The epoxide 2 was reacted with methanol in anhydrous dichloromethane catalyzed by para-toluenesulfonic acid to form an alcohol in $73 \%$ yield.

Predicting reaction mechanism by theoretical means, especially those catalyzed by metals or metal complexes, many possible reaction paths must be considered. The understanding of a reaction can be obtained only by theoretical calculation, but spectroscopic and experimental data are indispensable to deduce the mechanism. Measurements of reaction kinetics, isotope labeling, and detection of unstable intermediates are widely used to propose a mechanism of reaction. ${ }^{[16,17]}$

Theoretical methods are nowadays often employed to explain reaction mechanism, and we have used this tool to calculate the TSs for both candidate structures and used their energies to elucidate the structure of the alcohol.

Transition State 1 (TS1) was obtained by attack of methanol on carbon 5 whereas Transition State 2 (TS2) was formed by attack of the alcohol on carbon 6 . TS1 has led to product ( $r a c)-3 a$ whereas the product $(r a c)-3 b$ from the TS2 was not formed (Figure 1).

As presented in Table 1, the calculated potential energy, enthalpy, and Gibbs free energy for TS1 are smaller than for TS2 by $2.43,2.51$, and $2.13 \mathrm{kcal} \mathrm{mol}^{-1}$, respectively. This is in agreement with a kinetic reaction where TS1 is lower in energy; therefore, the barrier to reach product $(r a c)-3 \mathrm{a}$ is lower than the barrier to reach (rac)-3b.

The antiproduct formed by attack at carbon 5 of the epoxide ring was obtained exclusively, which is in line
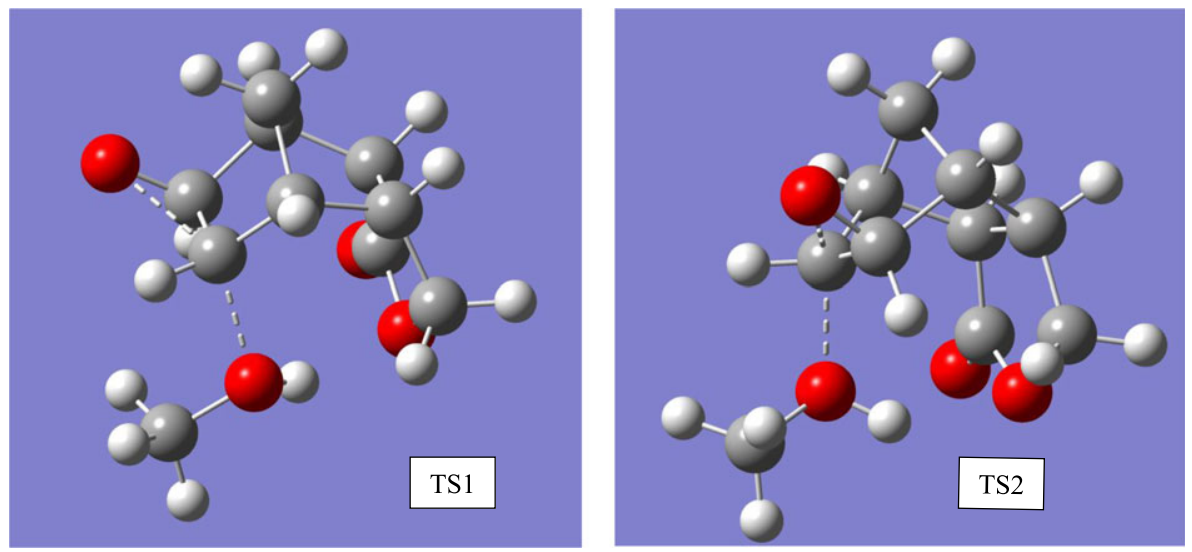

FIGURE 1 Calculated transition states (TS1 and TS2) for the reaction of the epoxide 2 with methanol 
TABLE 1 Calculated potential energy, enthalpy, and Gibbs free energy for Transition States 1 and 2 (TS1 and TS2)

\begin{tabular}{|llll|} 
& $\begin{array}{l}\text { Potential } \\
\text { energy }\end{array}$ & Enthalpy & $\begin{array}{l}\text { Gibbs free } \\
\text { energy }\end{array}$ \\
\hline TS1/ (Hartrees) & -689.99726681 & -689.749177 & -689.798633 \\
\hline TS2/ (Hartrees) & -689.9933881 & -689.745163 & -689.795225 \\
\hline $\begin{array}{c}\text { TS1-TS2/ } \\
\left(\mathrm{kcal} \mathrm{mol}^{-1}\right)\end{array}$ & 2.43 & 2.51 & 2.13 \\
\hline
\end{tabular}

with the calculated most favorable TS1. Therefore, compound ( $\mathrm{rac}$ )-3a is the kinetic product.

Compound ( $\mathrm{rac}$ )-3a was formed by epoxide opening as a racemic mixture because the starting epoxide 2 is a racemate. The cleavage of the epoxide with methanol was stereospecific and stereoselective. It is known that the epoxide opening is stereospecific; that is, the attack

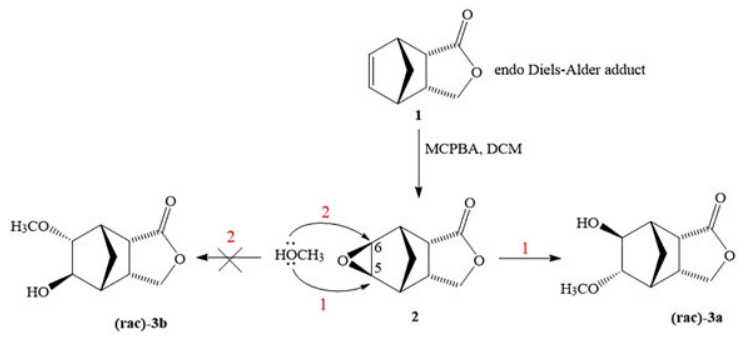

SCHEME 1 Epoxide opening with methanol occurs inverting the stereochemistry at the position where the alcohol is inserted. However the attack took place exclusively at position 5 of the epoxide ring as shown in Scheme 1. Therefore, besides the stereospecific character of the reaction, the epoxide opening was also stereoselective.

The proposed structure for compound ( $\mathrm{rac}$ )-3a based on the mechanistic theoretical calculation was confirmed by spectrometric analyses. The broad band at $3,413 \mathrm{~cm}^{-1}$ in the infrared due to hydroxyl stretching of the secondary alcohol (Figure S1) is a strong evidence of the epoxide opening.

The hydrogens $\mathrm{H} 5$ and $\mathrm{H} 6(\delta$ 4.00-4.05) of (rac)-3a (Figure S2) are chemically more deshielded than H5 and H6 ( $\delta 3.32-3.36)$ of Compound 2 (Figure S4). This can be explained by the longer $\mathrm{C}-\mathrm{O}(1.42 \AA)$ bond of the epoxide 2 than the $\mathrm{C}-\mathrm{OH}(1.41 \AA)$ and $\mathrm{C}-\mathrm{OR}$ $(1.40 \AA)$ of $(\mathrm{rac})-3 \mathrm{a}$. The greater distance of the oxygen from the carbon diminishes the electron-withdrawing effect of the electronegative atom making the protons more shielded. The deshielded position of H5 and H6 is another evidence of the epoxide opening.

The evidence of epoxide opening in the ${ }^{13} \mathrm{C}$ NMR are the signals referring to the carbons in $\delta 87.6$ (C6) and $\delta 71.5$ (C5). The signals of these carbons for the epoxide 2 are observed at $\delta 48.5$ (C6) and $\delta 47.3$ (C5), which can be seen in Figure S5. The reasoning given above for the chemical shifts differences observed in the ${ }^{1} \mathrm{H}$ NMR can also be used to explain the chemical shifts variations in the ${ }^{13} \mathrm{C} N M R$.

TABLE 2 The assigned and calculated NMR data for candidate structures ( $r a c)-3 a$ and ( $r a c)-3 b$

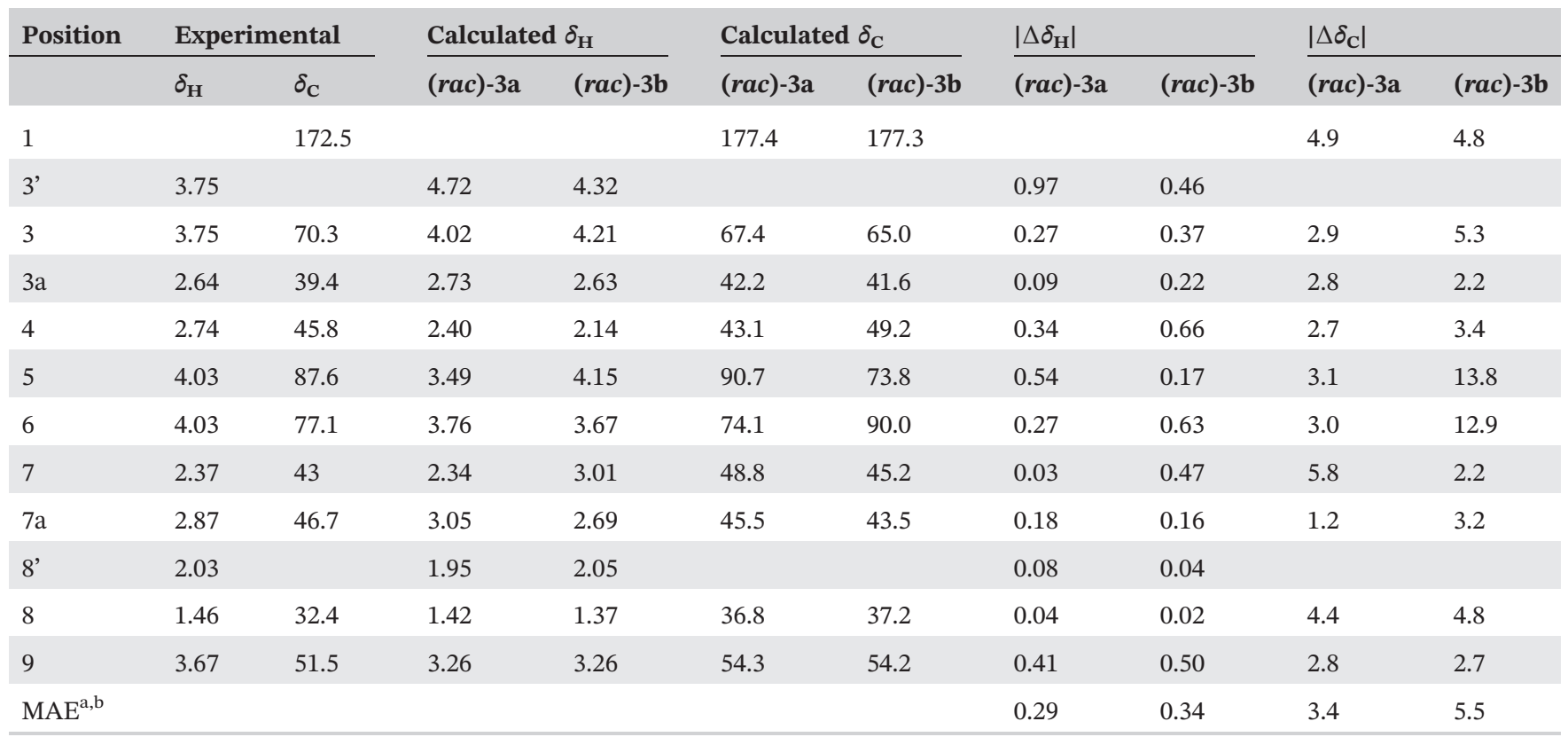

${ }^{\mathrm{a}}$ MAE: mean absolute error.

${ }^{\mathrm{b}}$ Calculations were carried out using the B3LYP/6-311+G(2d,p)//M06-2X/6-31+G(d,p) level of theory. 
The stereochemistry definition is mostly defined by NOE experiments; however, the signals of $\mathrm{H} 5$ and $\mathrm{H} 6$ are overlapped in the ${ }^{1} \mathrm{H}$ NMR. Thus, the unequivocal structure elucidation was assisted by calculating the ${ }^{1} \mathrm{H}$ and ${ }^{13} \mathrm{C}$ NMR chemical shifts at DFT level of theory for candidate structures ( $r a c)-3 a$ and $(r a c)-3 b$.

First, the calculated ${ }^{1} \mathrm{H}$ and ${ }^{13} \mathrm{C}$ NMR chemical shifts of (rac)-3a and ( $r a c)-3 b$ were compared with the experimental chemical shifts using the DP4 probability method. The first step is to calculate the ${ }^{13} \mathrm{C}$ and ${ }^{1} \mathrm{H}$ shifts for structures (rac)-3a and (rac)-3b as described in the 4 section (calculations) and tabulate the numbers (calculated $\delta_{\mathrm{H}}$ and calculated $\delta_{\mathrm{C}}$ in Table S1). These numbers are now transferred into the Web applet at http://www-jmg.ch.cam.ac.uk/tools/nmr/ DP4/, which automatically calculated the DP4 probability. The structure of the alcohol was defined as being ( $r a c$ )-3a with $100 \%$ probability comparing only carbon, only hydrogen and both carbon, and hydrogen chemical shifts (Figure S6).

Secondly, the calculated ${ }^{1} \mathrm{H}$ and ${ }^{13} \mathrm{C}$ NMR chemical shifts of ( $r a c)-3 a$ and ( $r a c)-3 b$ as described in the Experimental section (calculations) were tabulated (calculated $\delta_{\mathrm{H}}$ and calculated $\delta_{\mathrm{C}}$ in Table 2). The theoretical and experimental ${ }^{1} \mathrm{H}$ and ${ }^{13} \mathrm{C}$ NMR chemical shifts were compared and the MAE calculated. The computed MAE for the hydrogen chemical shifts for ( $r a c)-3 a$ was 0.29 , whereas for (rac)-3b was 0.34 . Consistent with the previous calculation, the MAE for the carbon has also matched (rac)-3a as the correct structure in detriment of (rac)-3b (Table 2).

The issue related to the chemical shift overlapping of $\mathrm{H} 5$ and $\mathrm{H} 6$ was circumvented by acetylating the alcohol with acetic anhydride as described in the Experimental section. This approach is not economical because of the extra synthetic step to confirm the structure of ( $\mathrm{rac}$ )-3a, which has already been defined by theoretical calculations and NMR analyses. The acetylation approach has worked by deshielding the signal of H6 because of the electron withdrawing effect of the acetyl group. The signals of the ester 4 have been fully assigned, and the Correlation Spectroscopy (COSY) correlations are indicated in Figure S7.

\section{3 | CONCLUSION}

Five new compounds were synthesized by stereospecific and stereoselective opening of the epoxide 2 with methanol, ethanol, propan-2-ol, propan-1-ol, and butan-1-ol. The association of theoretical calculations with NMR spectroscopy was critical for the structure elucidation of compound (rac)-3a because the hydrogens $\mathrm{H} 5$ and $\mathrm{H} 6$ overlapped in the ${ }^{1} \mathrm{H}$ NMR spectrum. Another approach used to define the structure of compound ( $r a c)-3 a$ was by acetylating the hydroxyl group, which induced the separation of $\mathrm{H} 5$ and $\mathrm{H} 6$ in the ${ }^{1} \mathrm{H}$ NMR spectrum.

\section{4 | EXPERIMENTAL}

\subsection{General experimental procedures}

The reactions were monitored by thin layer chromatography plates coated with silica gel in an ultraviolet chamber $^{[18]}$ at $254 \mathrm{~nm}$. Column chromatography was performed over silica gel (70-230 mesh). Infrared spectra were performed on a PerkinElmer Spectrum 1000 (thin film in $\mathrm{NaCl}$ plate), and the wave numbers are reported in $\mathrm{cm}^{-1}$. The mass spectra by electronic impact $(70 \mathrm{eV})$ were recorded on a Shimadzu GCMSQP5050A instrument. Mass spectra by chemical ionization (IQ) were obtained on GCMS-QP2010 Ultra SHIMADZU equipment using methane as the ionizing gas. Melting points are uncorrected and were obtained in MQAPF-301 melting point apparatus (Microquimica, Brazil).

\section{2 | NMR spectral methods}

NMR spectra were recorded on a Varian Mercury instrument $(300 \mathrm{MHz})$ with deuterated chloroform as solvent (the signal at $\delta=7.27 \mathrm{ppm}$ of the residual $\mathrm{CHCl}_{3}$ was used as reference in the ${ }^{1} \mathrm{H}$ NMR, and the signal of $\mathrm{CDCl} 3$ at $\delta=77 \mathrm{ppm}$ was used as reference in the ${ }^{13} \mathrm{C} \mathrm{NMR}$ ).

\subsection{1 | Rac-(3aS,4S,5S,6R,7R,7aS)-5,6- epoxyhexahydro-4,7- methanoisobenzofuran-1(3H)-one (2)}

The endo adduct 1 (1.14 g, $7.59 \mathrm{mmol})$ was solubilized in $100-\mathrm{mL}$ dichloromethane (DCM) in a round-bottomed flask. Then, MCPBA (2.64 g, $15.2 \mathrm{mmol}$ ) was added in small portions to the DCM solution. The mixture was stirred for $15 \mathrm{hr}$ and transferred to a separating funnel. The reaction mixture was washed with aqueous $\mathrm{Na}_{2} \mathrm{SO}_{3}$ $(20 \% \mathrm{w} / \mathrm{v}, 100 \mathrm{~mL})$, and the organic phase was separated and reserved. The aqueous phase was extracted with $\mathrm{DCM}(3 \times 100 \mathrm{~mL})$. The organic extracts were combined and washed with aqueous $\mathrm{Na}_{2} \mathrm{CO}_{3}(20 \% \mathrm{w} / \mathrm{v}, 15 \mathrm{~mL})$. The organic layer was dried over anhydrous $\mathrm{MgSO}_{4}$ and filtrated. The residue was purified by silica-gel column chromatography using hexane: ethyl acetate 1:1 as eluent 
to afford $1.24 \mathrm{~g}$ of 2 as a white solid (98\% yield, mp 120.9$\left.121.7^{\circ} \mathrm{C}\right)$.

$\mathrm{R}_{\mathrm{f}} 0.36$ (Hexane/Ethyl acetate 1:1).

IR (Film, NaCl, cm ${ }^{-1}$ ) $\bar{\nu}_{\text {max }}: 2997,2961,1761,1377$, 1186, 996, 846.

${ }^{1} \mathrm{H}$ NMR $\left(300 \mathrm{MHz}, \mathrm{CDCl}_{3}\right) ; \delta(\mathrm{J} / \mathrm{Hz}): 0.96(1 \mathrm{H}, \mathrm{d}$, $J=10.2, \mathrm{H} 8) ; 1.56\left(1 \mathrm{H}, \mathrm{d}, J=10.2, \mathrm{H} 8^{\prime}\right) ; 2.70-2.74(1 \mathrm{H}$, m, H4); 2.95-2.99 (1H, m, H7); 2.99-3.06 (1H, m, H3a); 3.11 (1H, dd, $J=10.3$, and $J=5.0, \mathrm{H} 7 \mathrm{a}) ; 3.32-3.36(2 \mathrm{H}$, m, H5, and H6); 4.26-4.41 (2H, m, H3, and H3').

${ }^{13} \mathrm{C}$ NMR (75 MHz, $\left.\mathrm{CDCl}_{3}\right) ; \delta: 29.3$ (C8); 39.2 (C7); 39.9 (C4); 41.3 (C3a); 45.5 (C7a); 47.3 (C5)*; 48.5 (C6)*; $67.6(\mathrm{C} 3) ; 176.7(\mathrm{C} 1)$.

MS (EI) $m / z$ (\%): 138 (11); 110 (13); 109 (20); 92 (17); 91 (25); 82 (42); 81 (100); 80 (11); 79 (49); 78 (19); 77 (45); 70 (27); 69 (57); 66 (17); 65 (14); 55 (17); 54 (27); 53 (29); 51 (21); 41 (22); 40 (12).

MS (CI) $m / z(\%): 167\left([\mathrm{M}+\mathrm{H}]^{+}, \mathrm{C}_{9} \mathrm{H}_{11} \mathrm{O}_{3}, 100\right) ; 121$ (36); 110 (27); 109 (43); 105 (12); 93 (34); 92 (16); 91 (25); 82 (38); 81 (83); 80 (14); 79 (56); 78 (24); 77 (45); 70 (33); 69 (70); 68 (11); 67 (15); 66 (14); 65 (13); 55 (10); 54 (12); 53 (15).

\subsection{2 | Rac-(3aS,4S,5R,6R,7R,7aS)-6- hydroxi-5-methoxyhexahydro-4,7- methanoisobenzofuran-1(3H)-one ((rac)- 3a)}

A mixture of epoxide 2 (0.30 g, 1,82 mmol), paratoluenesulfonic acid $(0.20 \mathrm{~g}, 1.16 \mathrm{mmol})$, anhydrous DCM $(5 \mathrm{~mL})$, and anhydrous methanol $(15 \mathrm{~mL})$ was refluxed for $12 \mathrm{hr}$ under nitrogen atmosphere. The methanol and DCM were evaporated under reduced pressure, and the residue was solubilized in $40 \mathrm{~mL}$ of DCM and transferred to a separating funnel. The organic phase was washed with 20-mL saturated $\mathrm{NaHCO}_{3}$ solution and saturated $\mathrm{NaCl}$ solution $(20 \mathrm{~mL})$. After this procedure, the organic phase was dried over anhydrous $\mathrm{MgSO}_{4}$, filtered, and concentrated under reduced pressure. The residue was purified by silica-gel column chromatography using DCM/ethyl acetate $2: 1$ as eluent to afford $0.26 \mathrm{~g}$ of ( $\mathrm{rac}$-) $3 \mathrm{a}$ as a white solid (73\% yield, $\mathrm{mp}$ $\left.56.7-57.2^{\circ} \mathrm{C}\right)$.

$\mathrm{R}_{\mathrm{f}} 0.34$ (DCM/Ethyl acetate 2:1).

IR (Film, $\mathrm{NaCl}, \mathrm{cm}^{-1}$ ) $\bar{\nu}_{\max }: 3413,2957,2885,1733$, 1441, 1357, 1201, 1057, 1033, 901.

${ }^{1} \mathrm{H}$ NMR $\left(300 \mathrm{MHz}, \mathrm{CDCl}_{3}\right) ; \delta(\mathrm{J} / \mathrm{Hz}): 1.46(1 \mathrm{H}, \mathrm{d}$, $J=10.8, \mathrm{H} 8) ; 2.03$ (1H, d, $J=10.8, \mathrm{H} 8$ ); 2.37 (1H, bs, H7); 2.60-2.69 (2H, m, H3a, and $\mathrm{OH}) ; 2.71-2.77(1 \mathrm{H}, \mathrm{m}$, $\mathrm{H} 4) ; 2.87(1 \mathrm{H}, \mathrm{dd}, J=10.8$, and $J=3.6, \mathrm{H} 7 \mathrm{a}) ; 3.67(3 \mathrm{H}$, s, H9); 3.73-3.76 (2H, m, H3, and H3'); 4.00-4.05 (2H, $\mathrm{m}, \mathrm{H} 5$, and $\mathrm{H6}$ ).
${ }^{13} \mathrm{C}$ NMR (75 MHz, $\mathrm{CDCl}_{3}$ ); $\delta: 32.4$ (C8); 39.4 (C3a); 43.0 (C7); 45.8 (C4); 46.7 (C7a); 51.5 (C9); 70.3 (C3); 77.1 (C6); 87.6 (C5); 172.5 (C1).

MS $m / z(\%): 198\left([\mathrm{M}]^{+}, \mathrm{C}_{10} \mathrm{H}_{14} \mathrm{O}_{4}, 1\right) ; 167(20) ; 166$ (22); 138 (14); 121 (16); 120 (10); 107 (14); 100 (17); 99 (100); 98 (9); 97 (11); 93 (13); 91 (15); 83 (14); 82 (43); 81 (31); 79 (36); 70 (14); 69 (35); 59 (13); 55 (29); 53 (25); 41 (51); 39 (43); 31 (20).

\subsection{3 | Rac-(3aS,4S,5R,6R,7R,7aS)-6-acetyl- 5-methoxyhexahydro-4,7- methanoisobenzofuran-1(3H)-one (4)}

A mixture of $3(0.05 \mathrm{~g}, 0.26 \mathrm{mmol})$, DMAP (0.02 g, $0.16 \mathrm{mmol})$, acetic anhydride $(0.07 \mathrm{~g}, 0.72 \mathrm{mmol})$, and DCM $(15 \mathrm{~mL})$ was stirred at room temperature for $2 \mathrm{hr}$. The mixture was transferred to a separating funnel, diluted with DCM $(15 \mathrm{~mL})$, and washed with water $(15 \mathrm{~mL})$. The organic phase was separated and dried over anhydrous $\mathrm{MgSO}_{4}$, filtered, and concentrated under reduced pressure. The residue was purified by silica-gel column chromatography using DCM/ethyl acetate 10:1 as eluent to afford $0.06 \mathrm{~g}$ of 4 as a colorless oil (98\% yield).

$\mathrm{R}_{\mathrm{f}} 0.41$ (DCM/Ethyl acetate 10:1).

IR (Film, $\mathrm{NaCl}, \mathrm{cm}^{-1}$ ) $\bar{\nu}_{\text {max }}: 2973,2889,1781,1735$, 1441, 1373, 1245, 1037.

${ }^{1} \mathrm{H}$ NMR $\left(300 \mathrm{MHz}, \mathrm{CDCl}_{3}\right) ; \delta(\mathrm{J} / \mathrm{Hz}): 1.51(1 \mathrm{H}, \mathrm{d}$, $J=11.0, \mathrm{H} 8) ; 1.99$ (1H, d, $J=11.0, \mathrm{H} 8$ '); $2.47(1 \mathrm{H}, \mathrm{sl}$, H7); 2.62-2.71 (1H, m, H3a); 2.72-2.78 (1H, m, H4); $2.89(1 \mathrm{H}, \mathrm{dd}, J=10.8$, and $J=3.7, \mathrm{H} 7 \mathrm{a}) ; 3.67(3 \mathrm{H}, \mathrm{s}$, H9); 3.70-3.82 (2H, m, H3 e H3'); 4.07 (1H, dl, $J=4.9$, H5); 4.87 (1H, sl, H6).

${ }^{13} \mathrm{C}$ NMR (75 MHz, $\mathrm{CDCl}_{3}$ ); $\delta: 21.0$ (C11); 32.7 (C8); 39.4 (C3a); 40.5 (C7); 45.9 (C4); 46.6 (C7a); 51.5 (C9); 70.3 (C3); 79.6 (C6); 85.3 (C5); 169.8 (C10); 171.8 (C1).

MS m/z (\%): 212 (21); 209 (13); 197 (18); 180 (48); 152 (12); 148 (12); 139 (13); 137 (15); 121 (17); 120 (16); 109 (11); 107 (15); 99 (34); 93 (17); 91 (15); 82 (14); 81 (28); 79 (73); 69 (18); 59 (12); 55 (11); 53 (13); 45 (19); 43 (100); 41 (21).

\section{5 | CALCULATIONS}

\section{1 | Transition state}

The transition state Guess (TS-Guess) was generated by placing the methanol at the opposite face with respect to the epoxide oxygen and a Methanol-O-C-epoxide distance of $1.8 \AA$. The $\mathrm{S}_{\mathrm{N}} 2$ mechanism was proposed because the epoxide was opened with five distinct alcohols affording the antiproduct exclusively. The $\mathrm{S}_{\mathrm{N}} 1$ mechanism would afford the syn- addition as the main 
product because the endo face is more hindered. Placing the Methanol-O-C-epoxide closer than $1.8 \AA$ (e.g., $1.44 \AA$ ) resulted in a structure where the epoxide is completely open (C-O distance in epoxide $2.44 \AA$ ). When starting from such a poor initial TS geometry, the search fails. The calculations were performed considering attack on both carbons of the epoxide ring, and the potential energy, enthalpy, and Gibbs free energy for both transitions states were compared with find the most favorable intermediate. The most favorable intermediate will necessarily lead to the kinetic product. The Cartesian coordinates for the initial TSGuess calculation are presented at Tables S2 (initialGuess-TS1) and S4 (initial-Guess-TS2).

The Guess structure was firstly optimized at B3LYP/6-31+G(d,p) level of theory and further optimized with the M062x functional and $6-31+G(d, p)$ basis set (Tables S3, S5, S6, and S7). The optimized Guess structure was used as starting structure for the TS search. The TS was calculated with the following route section, which was set in the input file for Gaussian calculation:

\# $\mathrm{m} 062 \mathrm{x} / 6-31+\mathrm{G}(\mathrm{d}, \mathrm{p}) \quad$ opt $=$ (ts,calcfc) freq guess $=$ read geom $=$ (Allcheck,newdefinition $)$.

Once the calculation has finished, the imaginary frequency was verified to check if the motion of the molecules under that frequency agree with the expected reaction.

\section{2 | Mean absolute error}

The geometry structure drawn in Spartan 16 (Wavefunction) ${ }^{[19]}$ was optimized using the minimize tool, and conformer distribution was performed using Molecular Mechanics Force Field. It was found six conformers for (rac)-3a and (rac)-3b.

These conformers were submitted to geometry optimization and frequency calculation using Gaussian $09^{[20]}$ at M06-2X/6-31+G(d,p) level of theory. NMR shielding tensor values were calculated at B3LYP/6-311+G(2d,p) level of theory. The relative free energies obtained from frequency calculations are used to determine the Boltzmann-weighting factors. The mole fractions applied to the computed NMR shielding tensors for each nucleus of each isolated conformer affords the weighted tensors. The Boltzmann-weighted average NMR-shielding tensors for the candidate structure are obtained by adding the weighted tensors across all conformers. Scaling factors (slope $=-1.0767$, intercept $=31.9477)$ are applied to the ${ }^{1} \mathrm{H}$ NMR shielding tensors (B3LYP/6-311+G(2d,p)// M06-2X/6-31+G(d,p) to calculate the ${ }^{1} \mathrm{H}$ NMR chemical shifts. Scaling factors (slope $=-1.0522$, intercept $=181.2412)$ are applied to the ${ }^{13} \mathrm{C}$ NMR shielding tensors $\quad(B 3 L Y P / 6-311+G(2 d, p) / / M 06-2 X / 6-31+G(d, p)$ to calculate the ${ }^{13} \mathrm{C}$ NMR chemical shifts. ${ }^{[21,22]}$ The computed NMR shielding tensors are converted into referenced chemical shifts by $\delta=(\sigma-$ intercept $) /$ slope, where $\delta$ is the referenced chemical shift and $\sigma$ is the computed NMR shielding tensor.

The MAE is calculated by making the difference between the calculated $\left(\delta_{\text {calc }}\right)$ and experimental $\left(\delta_{\text {exp }}\right)$ chemical shifts averaged across all nuclei $\left(\Sigma_{\mathrm{n}}\left|\delta_{\text {calc }}-\delta_{\text {exp }}\right| / n\right)$.

\section{3 | DP4}

The conformers found as described above were subjected to single-point calculations of energy and gauge-including atomic orbitals shielding tensors at the B3LYP/6-31G(d,p) level in the gas phase. The shielding tensors were converted into referenced chemical shifts by subtracting the computed shielding tensors of tetramethylsilane calculated at the same level of theory $\left({ }^{1} \mathrm{H}=31.8819\right.$; $\left.{ }^{13} \mathrm{C}=183.7949\right)$. The chemical shift values were Boltzmann averaged using the single-point energy obtained from the calculation. DP4 analysis was accomplished by inputting computed and experimental chemical shifts into the DP4 analysis tool (located at: http:// www-jmg.ch.cam.ac.uk/tools/nmr/DP4/). ${ }^{[5,14]}$

\section{ACKNOWLEDGEMENTS}

We are grateful to $\mathrm{CNPq}$ Conselho Nacional de Desenvolvimento Científico e Tecnológico, CAPES Coordenação de Aperfeiçoamento de Pessoal de Nível Superior-Finance Code 001, RQ-MG, and FAPEMIG Fundação de Amparo à Pesquisa do Estado de Minas Gerais, Brasil for financial support.

\section{ORCID}

Elson S. Alvarenga (DD https://orcid.org/0000-0002-7333-0006

\section{REFERENCES}

[1] N. Katoh, T. Nakahata, S. Kuwahara, Tetrahedron 2008, 64, 9073. https://doi.org/10.1016/j.tet.2008.07.023

[2] M. G. Teixeira, E. S. Alvarenga, M. F. Pimentel, M. C. Picanço, J. Braz. Chem. Soc. 2015, 26, 2279. https://doi.org/10.5935/ 0103-5053.20150217

[3] W. L. T. Kan, C. H. Cho, J. A. Rudd, G. Lin, J. Ethnopharmacol. 2008, 120, 36. https://doi.org/10.1016/j.jep.2008.07.027

[4] J. Sauer, Angew. Chem. Int. Ed. 1967, 6, 16. https://doi.org/ 10.1002/anie.196700161

[5] M. G. Teixeira, E. S. Alvarenga, Magn. Reson. Chem. 2016, 54, 623. https://doi.org/10.1002/mrc.4411 
[6] M. M. Zanardi, A. G. Suárez, A. M. Sarotti, J. Org. Chem. 2017, 82, 1873. https://doi.org/10.1021/acs.joc.6b02129

[7] F. Liu, Y. Liang, K. N. Houk, Acc. Chem. Res. 2017, 50, 2297. https://doi.org/10.1021/acs.accounts.7b00265

[8] R. P. Oliveira, A. J. Demuner, E. S. Alvarenga, L. C. A. Barbosa, T. de Melo Silva, J. Mol. Struct. 2018, 1152, 337. https://doi.org/ 10.1016/j.molstruc.2017.09.065

[9] A. Bagno, F. Rastrelli, G. Saielli, J. Phys. Chem. A 2003, 107, 9964. https://doi.org/10.1021/jp0353284

[10] A. Bagno, Chem. A Eur. J. 2001, 7, 1652. https://doi.org/ 10.1002/1521-3765(20010417)7:8<1652::AID-CHEM16520>3.0. $\mathrm{CO} ; 2-\mathrm{V}$

[11] S. G. Smith, J. M. Goodman, J. Am. Chem. Soc. 2010, 132, 12946. https://doi.org/10.1021/ja105035r

[12] M. A. Muñoz, P. Joseph-Nathan, Magn. Reson. Chem. 2010, 48, 458. https://doi.org/10.1002/mrc.2601.

[13] M. Pisklak, J. Kossakowski, M. Perliński, I. Wawer, J. Mol. Struct. 2004, 698, 93. https://doi.org/10.1016/j.molstruc.2004.04.026

[14] G. C. Resende, E. S. Alvarenga, P. H. Willoughby, J. Mol. Struct. 2015, 1101, 212. https://doi.org/10.1016/j.molstruc.2015.08.028

[15] N. Grimblat, M. M. Zanardi, A. M. Sarotti, J. Org. Chem. 2015, 80, 12526. https://doi.org/10.1021/acs.joc.5b02396

[16] G.-J. Cheng, X. Zhang, L. W. Chung, L. Xu, Y.-D. Wu, J. Am. Chem. Soc. 2015, 137, 1706. https://doi.org/10.1021/ja5112749

[17] B. Chen, M. E. Scott, B. A. Adams, D. A. Hrovat, W. T. Borden, M. Lautens, Org. Lett. 2014, 16, 3930. https://doi.org/10.1021/ ol501710m

[18] E. S. Alvarenga, W. A. Saliba, B. G. Milagres, Quim. Nova 2005, 28, 927. https://doi.org/10.1590/S0100-40422005000500034.

[19] W. Hehre, S. Ohlinger, Spartan'16 Tutorial and User's Guide, Wavefunction, Inc., Irvine, California 2016 http://www. wavefun.com.
[20] M. J. Frisch, G. W. Trucks, H. B. Schlegel, G. E. Scuseria, M. A. Robb, J. R. Cheeseman, G. Scalmani, V. Barone, B. Mennucci, G. A. Petersson, H. Nakatsuji, M. Caricato, X. Li, H. P. Hratchian, A. F. Izmaylov, J. Bloino, G. Zheng, J. L. Sonnenberg, M. Hada, M. Ehara, K. Toyota, R. Fukuda, J. Hasegawa, M. Ishida, T. Nakajima, Y. Honda, O. Kitao, H. Nakai, T. Vreven, J. A. Montgomery Jr., J. E. Peralta, F. Ogliaro, M. Bearpark, J. J. Heyd, E. Brothers, K. N. Kudin, V. N. Staroverov, R. Kobayashi, J. Normand, K. Raghavachari, A. Rendell, J. C. Burant, S. S. Iyengar, J. Tomasi, M. Cossi, N. Rega, J. M. Millam, M. Klene, J. E. Knox, J. B. Cross, V. Bakken, C. Adamo, J. Jaramillo, R. Gomperts, R. E. Stratmann, O. Yazyev, A. J. Austin, R. Cammi, C. Pomelli, J. W. Ochterski, R. L. Martin, K. Morokuma, V. G. Zakrzewski, G. A. Voth, P. Salvador, J. J. Dannenberg, S. Dapprich, A. D. Daniels, €. O. Farkas, J. B. Foresman, J. V. Ortiz, J. Cioslowski, D. J. Fox, Gaussian '09, Revision D.1, Gaussian, Inc., Wallingford CT 2009.

[21] P. H. Willoughby, M. J. Jansma, T. R. Hoye, Nat. Protoc. 2014, 9, 643. https://doi.org/10.1038/nprot.2014.042.

[22] M. W. Lodewyk, M. R. Siebert, D. J. Tantillo, Chem. Rev. 2012, 112, 1839. https://doi.org/10.1021/cr200106v

\section{SUPPORTING INFORMATION}

Additional supporting information may be found online in the Supporting Information section at the end of the article.

How to cite this article: Alvarenga ES, Teixeira MG, Lopes DT, Demuner AJ. Computation and structural elucidation of compounds formed via epoxide alcoholysis. Magn Reson Chem. 2019;57: S101-S107. https://doi.org/10.1002/mrc.4818 